\title{
Testing of Patient Sample or Reference Material Using Reference Method
}

National Cancer Institute

\section{Source}

National Cancer Institute. Testing of Patient Sample or Reference Material Using

Reference Method. NCI Thesaurus. Code C139453.

The investigation employed relevant empirical testing of a patient sample or reference material using an appropriate reference method to the device (usually an IVD) involved in the reported adverse event in order to support the identification of possible causes for the adverse event. Relevant testing would typically be based on test methods used for evaluating safety and performance as described in the latest relevant standards. 